\title{
An improved data reduction method for transient liquid crystal thermography on film cooling measurements
}

\author{
Ping-Hei Chen *, Pei-Pei Ding, Di Ai \\ Department of Mechanical Engineering, National Taiwan University, No. 1, Sec. 4, Roosevelt Road, Taipei 10617, Taiwan, ROC \\ Received 19 October 1999; received in revised form 28 April 2000
}

\begin{abstract}
This study proposes an improved data reduction method for the applications of transient liquid crystal thermography on film cooling effectiveness measurements. On the evaluations of film cooling effectiveness and heat transfer coefficient, an "equivalent step temperature" (EST) is proposed to replace the Duhamel's superposition principle which is conventionally used to account for the actual temperature rises in both free-stream and injection flows rather than the ideal step temperature changes. For obtaining both values at over thousands of measured locations, the current data reduction method can effectively reduce the calculation time as compared with the conventional Duhamel's superposition method, but adds only negligible errors. (c) 2001 Elsevier Science Ltd. All rights reserved.
\end{abstract}

\section{Introduction}

Encapsulated thermochromic liquid crystal changes its molecular arrangement with temperature variation and reflects different color. A full field temperature measurement with high spacial resolution can be achieved by capturing the color-change history on a liquid crystal coated test surface through an image processing system. Therefore, it is more convenient and powerful than conventional measurement techniques. In recent years, significant efforts have been taken to develop and further improve this technique for the application on heat transfer studies.

Baughn [1] completed a review on both the theoretical and experimental applications of liquid crystal thermography in measuring heat transfer coefficient, including the steady state and transient techniques. For the transient technique, a one-dimensional semi-infinite physical model of test piece was assumed, and the transient temperature response of test piece was produced by an immediate rise or decrease of the freestream temperature. Other novel transient techniques,

\footnotetext{
${ }^{*}$ Corresponding author. Tel.: +886-2-27523501; fax: +886-223671755.

E-mail address: phchen@ccms.ntu.edu.tw (P.-H. Chen).
}

such as radiant heating on side wall [2] and periodic heating on free-stream [3], are more complicated in the experimental design and theoretical formulation than the 1-D semi-infinite transient technique.

As a result of the advancement of color image processing system, the 1-D semi-infinite transient technique is widely adopted recently. However, poor accuracy and long data processing time is the major drawback of the technique. To obtain more reasonable results, improvement has to be requested in the experimental operation, data reduction method, or the image processing approach. For instance, Wang et al. [4] developed an automatic processing system that can record the complete hue history of color change. Two methods that employ the information redundancy to obtain heat transfer coefficient were also presented, the so-called "hue history time scaling method" and the "temperature history matching method". Both methods can improve the accuracy of the transient measurement technique.

In order to reduce the considerable error in analyzing long internal cooling channel, Chyu et al. [5] compared several data reduction methods for determining both heat transfer coefficient and local fluid temperature. One of these methods that based on an assumption of invariant local heat flux can effectively reduce both the error and the data processing time. Wolfersdorf et al. [6] proposed a simplified model of local fluid temperature to 


\begin{tabular}{|c|c|c|c|}
\hline \multicolumn{2}{|c|}{ Nomenclature } & $Z$ & coordinate normal to the surface, $\mathrm{m}$ \\
\hline$B$ & dimensionless temperature function & \multicolumn{2}{|c|}{ Greek symbols } \\
\hline$d$ & injection hole diameter, $\mathrm{m}$ & $\alpha$ & thermal diffusivity of test surface, $\mathrm{m}^{2} / \mathrm{s}$ \\
\hline$h$ & $\begin{array}{l}\text { heat transfer coefficient defined on wall and } \\
\text { film temperature, } \mathrm{W} / \mathrm{m}^{2} \mathrm{~K}\end{array}$ & & $\begin{array}{l}\text { spanwise angle of injection hole, deg. } \\
\text { displacement thickness, m }\end{array}$ \\
\hline$h_{\mathrm{EST}}$ & $\begin{array}{l}\text { given } h \text { value for determining EST in Eqs. (12) } \\
\text { and (13), W/m } / \mathrm{m}^{2} \mathrm{~K}\end{array}$ & $\begin{array}{l}\gamma \\
\eta\end{array}$ & $\begin{array}{l}\text { inclination angle of injection hole, deg. } \\
\text { film cooling effectiveness }\end{array}$ \\
\hline $\bar{h}$ & $\begin{array}{l}\text { spanwise averaged heat transfer coefficient, } \\
\mathrm{W} / \mathrm{m}^{2} \mathrm{~K}\end{array}$ & & $\begin{array}{l}\text { spanwise averaged film cooling effectiveness } \\
\text { dynamic viscosity of free-stream, } \mathrm{kg} / \mathrm{m} \mathrm{s}\end{array}$ \\
\hline$k$ & thermal conductivity of test surface, $\mathrm{W} / \mathrm{m} \mathrm{K}$ & $w$ & uncertainty \\
\hline$L$ & injection hole length, $\mathrm{m}$ & $\rho$ & density, $\mathrm{kg} / \mathrm{m}^{3}$ \\
\hline$M$ & blowing ratio $=\rho_{\mathrm{c}} u_{\mathrm{c}} / \rho_{\mathrm{m}} u_{\mathrm{m}}$ & $\tau$ & Duhamel's integration time, $\mathrm{s}$ \\
\hline$R e_{\mathrm{d}}$ & $\begin{array}{l}\text { free-stream Reynolds number based on the } \\
\text { injection hole diameter }=\rho_{\mathrm{m}} u_{\mathrm{m}} d / \mu\end{array}$ & $\phi$ & direct variables related to $h$ and $\eta$ \\
\hline$P$ & pitch of injection holes, $\mathrm{m}$ & \multicolumn{2}{|c|}{ Subscripts } \\
\hline$T$ & temperature, ${ }^{\circ} \mathrm{C}$ & 0 & initial condition \\
\hline$T u$ & free-stream turbulent intensity, $\%$ & EST & equivalent step temperature \\
\hline$t$ & time, $\mathrm{s}$ & 1 & the first test \\
\hline$u$ & velocity, $\mathrm{m} / \mathrm{s}$ & 2 & the second test \\
\hline$X$ & $\begin{array}{l}\text { axial distance from the center of injection } \\
\text { hole, } \mathrm{m}\end{array}$ & & $\begin{array}{l}\text { the } s \text { th time divided block } \\
\text { free-stream }\end{array}$ \\
\hline$Y$ & spanwise coordinate along the injection & $\mathrm{r}$ & reference condition \\
\hline & hole, $\mathrm{m}$ & $\mathrm{w}$ & surface of test piece \\
\hline
\end{tabular}

derive the heat transfer in the long channel problem. The result of local heat transfer coefficient also showed better accuracy than before.

Recently, the transient liquid crystal thermography is often introduced in the film cooling measurement that is classified as a three-temperature system (free-stream temperature, wall temperature and injection flow temperature) in heat transfer studies. Therefore, the improved data reduction methods mentioned above that are restricted to the two-temperature system (local fluid temperature and wall temperature) cannot be proceeded to the film cooling measurement. Because both the heat transfer coefficient and film cooling effectiveness are unknown at every fixed measured position, two equations are needed to solve the two parameters. Correspondingly, two experimental tests with different local fluid temperatures, which may produce different temperature responses of the test surface, are conducted to construct the two equations. Therefore, this "two-test method" is the base of theoretical formulation for the transient liquid crystal thermography of a threetemperature system [7]. The different local fluid temperatures are usually achieved by altering the injection flow temperature under fixed free-stream conditions.

A step temperature change of the injection flow is generally achieved by preheating it to the required temperature and is by-passed away by using a three-way valve. The flow is then diverted to the test piece to initiate the transient experiment. The actual temperature rise in the method of diverting injection flow is an approximately step temperature rise. Since this is a linear heat transfer system, the discrepancy can be modified by the Duhamel's superposition principle. Even if the freestream flow is also supplied by means of preheating and diverting flow, an "ideal" step temperature rise is still impossible to be achieved, and the Duhamel's superposition should be applied to modify the two equations in the two-test method [8-10]. To determine reasonable heat transfer coefficient and film cooling effectiveness in film cooling studies, this modification cannot be avoided. However, it will take more time and also complicate the data iterations, especially in the cases of ten thousands of analyzed locations (pixels). A distinct approach was proposed by Drost et al. [11] to fit the injection temperature rising curve by a fifth-order polynomial. The analytical solution of the transient wall temperature response, which was used for determining the heat transfer coefficient and film cooling effectiveness, was then obtained by taking the Laplace transformation.

This paper proposes an "equivalent step temperature" (EST) method to simplify the conventional Duhamel's superposition calculation. This new data reduction method is a novel idea that serves as a preprocessor of the calculation and is independent of the number of iteration steps. This method effectively 
reduces the calculation time, especially for large number of analyzed pixels, long time period for liquid crystal color change history, or multi-test experiment, and the error that may arise from the simplification is negligible. The proposed EST method is verified in this study by using a film cooling model of flat plate with one row of injection holes.

In the published literature dealing with the transient liquid crystal thermography, the degree of idealizations in the step heating equipment has not been discussed yet. The present EST method offers a quantitative standard in realizing the adequacy of the step heating equipment.

In this paper, a flat plate film cooling model $\left(P / d=3, M=0.5, R e_{\mathrm{d}}=2200\right)$ with a row of injection holes (spanwise angle $\beta=0^{\circ}$, inclination angle $\gamma=35^{\circ}$ ) was employed to investigate the application of the EST method to film cooling measurement.

\section{Theory}

In film cooling measurement, more complicated flow and temperature fields will be formed due to the mixing of free-stream and the injection flow. The temperature field becomes a three-temperature system consists of the free-stream temperature $T_{\mathrm{m}}$, wall surface temperature $T_{\mathrm{w}}$, and injection flow temperature $T_{\mathrm{c}}$. The illustration of the heat transfer system is shown in Fig. 1. The physical model of the transient liquid crystal thermography can be simplified and described by a transient, one-dimensional heat conduction equation with constant property over a semi-infinite solid

$\frac{\partial^{2} T}{\partial Z^{2}}=\alpha \frac{\partial T}{\partial t}$

with boundary conditions

$Z=0, \quad-k \frac{\partial T}{\partial Z}=h\left(T_{\mathrm{w}}-T_{\mathrm{r}}\right)$

$Z \rightarrow \infty, \quad T=T_{0}$

and initial condition

$t=0, \quad T=T_{0}$,

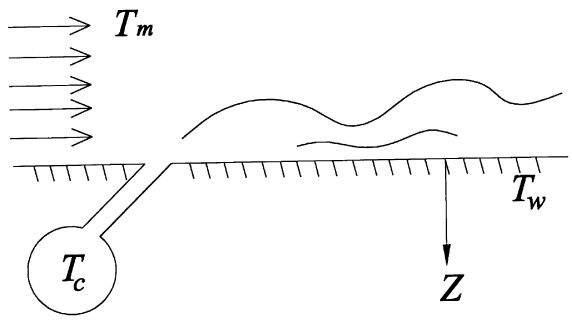

Fig. 1. Three-temperature system with film cooling effect. where $T_{0}$ is the initial temperature of the wall, and $T_{\mathrm{r}}$ is the reference temperature which will be the film temperature that drives the heat transfer phenomenon.

The temperature variation versus time on the wall surface, where the liquid crystal is sprayed in the experiment, is the solution at $Z=0$. That is

$\frac{T_{\mathrm{w}}-T_{0}}{T_{\mathrm{r}}-T_{0}}=1-\exp \left(\frac{h^{2} \alpha t}{k^{2}}\right) \operatorname{erfc}\left(\frac{h \sqrt{\alpha t}}{k}\right)$.

With the film cooling effect, $T_{\mathrm{r}}$ can be expressed as

$T_{\mathrm{r}}=(1-\eta) T_{\mathrm{m}}+\eta T_{\mathrm{c}}$,

where the film cooling effectiveness $\eta$ is defined as

$\eta=\frac{T_{\mathrm{r}}-T_{\mathrm{m}}}{T_{\mathrm{c}}-T_{\mathrm{m}}}$.

For simplicity, define a function $B$ as

$B(x)=1-\exp \left(x^{2}\right) \operatorname{erfc}(x)$.

Function $B$ is an increasing function, with

$B=0 \quad$ as $x=0$

and

$B \rightarrow 1 \quad$ if $x \rightarrow \infty$.

Eqs. (5) and (7) are substituted into Eq. (4), which becomes

$\frac{T_{\mathrm{w}}-T_{0}}{\eta\left(T_{\mathrm{c}}-T_{\mathrm{m}}\right)+T_{\mathrm{m}}-T_{0}}=B\left(\frac{h \sqrt{\alpha t}}{k}\right)$.

\subsection{Conventional Duhamel's superposition method}

For the film cooling measurement, the effect of fluid density difference on flow field, resulted from the temperature difference between $T_{\mathrm{m}}$ and $T_{\mathrm{c}}$, could be neglected within first order variation [12]. Therefore, $h$ and $\eta$ can be assumed to be independent of the temperature field, and $T_{\mathrm{m}}$ and $T_{\mathrm{c}}$ can be any arbitrary constant temperatures in Eq. (8). However, a step temperature rise of either $T_{\mathrm{m}}$ or $T_{\mathrm{c}}$ is physically impossible during the transient experiment. Both $T_{\mathrm{m}}$ and $T_{\mathrm{c}}$ will vary with time, and the boundary conditions of the linear governing equation (Eq. (1)) are functions of time too. Therefore, the temperature response on wall surface could be modified by convolution integration as

$$
\begin{aligned}
T_{\mathrm{w}}-T_{0}= & {\left[\eta\left(T_{\mathrm{c}, 0}-T_{\mathrm{m}, 0}\right)+T_{\mathrm{m}, 0}-T_{0}\right] B\left(\frac{h \sqrt{\alpha t}}{k}\right) } \\
& +\left[\eta\left(\dot{T}_{\mathrm{c}}(t)-\dot{T}_{\mathrm{m}}(t)\right)+\dot{T}_{\mathrm{m}}(t)\right] \\
& * B\left(\frac{h \sqrt{\alpha t}}{k}\right),
\end{aligned}
$$

where subscript 0 represents the initial time value of function, and the symbol $*$ is the convolution operator. 
The numerical form of Eq. (9) is the well-known Duhamel's superposition. After conducting two tests, $h$ and $\eta$ can be solved by the two equations below

$$
\begin{aligned}
& T_{\mathrm{w}, 1}-T_{0,1}=\left[\eta\left(T_{\mathrm{c}, 0,1}-T_{\mathrm{m}, 0,1}\right)+T_{\mathrm{m}, 0,1}-T_{0,1}\right] B\left(\frac{h \sqrt{\alpha t_{1}}}{k}\right) \\
& +\left\{\eta \left[\sum_{s=1}^{n} B\left(\frac{h \sqrt{\alpha\left(t_{1}-\tau_{s}\right)}}{k}\right) \Delta T_{\mathrm{c}, s, 1}\right.\right. \\
& \left.-\sum_{s=1}^{n} B\left(\frac{h \sqrt{\alpha\left(t_{1}-\tau_{s}\right)}}{k}\right) \Delta T_{\mathrm{m}, s, 1}\right] \\
& \left.+\sum_{s=1}^{n} B\left(\frac{h \sqrt{\alpha\left(t_{1}-\tau_{s}\right)}}{k}\right) \Delta T_{\mathrm{m}, s, 1}\right\} \text {, } \\
& T_{\mathrm{w}, 2}-T_{0,2}=\left[\eta\left(T_{\mathrm{c}, 0,2}-T_{\mathrm{m}, 0,2}\right)+T_{\mathrm{m}, 0,2}-T_{0,2}\right] B\left(\frac{h \sqrt{\alpha t_{2}}}{k}\right) \\
& +\left\{\eta \left[\sum_{s=1}^{n} B\left(\frac{h \sqrt{\alpha\left(t_{2}-\tau_{s}\right)}}{k}\right) \Delta T_{\mathrm{c}, s, 2}\right.\right. \\
& \left.-\sum_{s=1}^{n} B\left(\frac{h \sqrt{\alpha\left(t_{2}-\tau_{s}\right)}}{k}\right) \Delta T_{\mathrm{m}, s, 2}\right] \\
& \left.+\sum_{s=1}^{n} B\left(\frac{h \sqrt{\alpha\left(t_{2}-\tau_{s}\right)}}{k}\right) \Delta T_{\mathrm{m}, s, 2}\right\} \text {. }
\end{aligned}
$$

The subscripts 1 and 2 in Eqs. (10) and (11) denote the first test and the second test, respectively. The times taken $\left(t_{1}\right.$ and $\left.t_{2}\right)$ to reach the threshold temperature during liquid crystal color change will be measured, and the temperature histories of both free-stream and injection flows will be recorded simultaneously. The modification of temperature histories by Duhamel's superposition in the determinations of local $h$ and $\eta$ values is necessary as long as the free-stream and injection flows are heated. If the coated liquid crystal takes longer time to reach the threshold color during a test, longer processing time will be needed.

\subsection{The equivalent step temperature method}

The conventional Duhamel's superposition can be simplified by the present proposed EST method. The ESTs of free-stream $\left(T_{\mathrm{m}, \mathrm{EST}}\right)$ and injection flow $\left(T_{\mathrm{c}, \text { EST }}\right)$ are, respectively, defined as

$$
\begin{gathered}
T_{\mathrm{m}, \mathrm{EST}}(h, t) \equiv \frac{B\left(\frac{h \sqrt{\alpha t}}{k}\right) * \dot{T}_{\mathrm{m}}(t)}{B\left(\frac{h \sqrt{\alpha t}}{k}\right)}+T_{\mathrm{m}, 0}, \\
T_{\mathrm{c}, \mathrm{EST}}(h, t) \equiv \frac{B\left(\frac{h \sqrt{\alpha t}}{k}\right) * \dot{T}_{\mathrm{c}}(t)}{B\left(\frac{h \sqrt{\alpha t}}{k}\right)}+T_{\mathrm{c}, 0} .
\end{gathered}
$$

Replacing both the free-stream temperature and injection flow temperatures in Eq. (9) by the above definitions of EST, and rearranged to obtain

$\frac{T_{\mathrm{w}}-T_{0}}{\eta\left(T_{\mathrm{c}, \mathrm{EST}}-T_{\mathrm{m}, \mathrm{EST}}\right)+T_{\mathrm{m}, \mathrm{EST}}-T_{0}}=B\left(\frac{h \sqrt{\alpha t}}{k}\right)$.

A comparison between Eqs. (14) and (8) showed that the two equations have almost the same forms, except the constant step temperatures of $T_{\mathrm{m}}$ and $T_{\mathrm{c}}$ have been replaced by $T_{\mathrm{m} \text {.EST }}$ and $T_{\mathrm{c} \text {.EST }}$. The step temperature history $\left(T_{\mathrm{m}}(t)\right.$ or $\left.T_{\mathrm{c}}(t)\right)$ is correspondingly transferred to an ideal step temperature at every time instance by applying Eq. (12) or Eq. (13), and is termed as the EST $\left(T_{\mathrm{m}, \mathrm{EST}}(h, t)\right.$ or $\left.T_{\mathrm{c}, \mathrm{EST}}(h, t)\right)$ after the transformation in the present study. After conducting two tests, $h$ and $\eta$ in Eq. (14) can be solved by the two equations

$$
\begin{gathered}
\frac{T_{\mathrm{w}}-T_{0,1}}{\eta\left(T_{\mathrm{c}, \mathrm{EST}, 1}-T_{\mathrm{m}, \mathrm{EST}, 1}\right)+T_{\mathrm{m}, \mathrm{EST}, 1}-T_{0,1}}=B\left(\frac{h \sqrt{\alpha t_{1}}}{k}\right), \\
\frac{T_{\mathrm{w}}-T_{0,2}}{\eta\left(T_{\mathrm{c}, \mathrm{EST}, 2}-T_{\mathrm{m}, \mathrm{EST}, 2}\right)+T_{\mathrm{m}, \mathrm{EST}, 2}-T_{0,2}}=B\left(\frac{h \sqrt{\alpha t_{2}}}{k}\right) .
\end{gathered}
$$

The EST is basically a function of $h$ and $t$, and it is proved to be insensitive to the variation of $h$ in the present experimental results. Therefore, the $h$ values in Eqs. (12) and (13) can be determined at a constant value as $h_{\mathrm{EST}}$.

$T_{\mathrm{m}, \mathrm{EST}}(h, t) \cong T_{\mathrm{m}, \mathrm{EST}}\left(h_{\mathrm{EST}}, t\right)$,

$T_{\mathrm{c}, \mathrm{EST}}(h, t) \cong T_{\mathrm{c}, \mathrm{EST}}\left(h_{\mathrm{EST}}, t\right)$.

\section{Test facility}

The basic equipment design for the present transient heating technique is different from the past literature. The present study adopted a wire-screen heater for the heating of free-stream and injection flow. The initial temperature of the test section was maintained at room temperature. When the transient experiment is initiated, the only procedure that has to be taken is to switch on the heaters. Therefore, the flow pattern can be firmly maintained. Four main parts of the test system in this transient liquid crystal experiment which include the free-stream flow system, the test piece model, the injection flow system, and the image processing system are shown in Fig. 2(a).

The free-stream flow system was constructed by a suction type wind tunnel. A convergent nozzle with an 


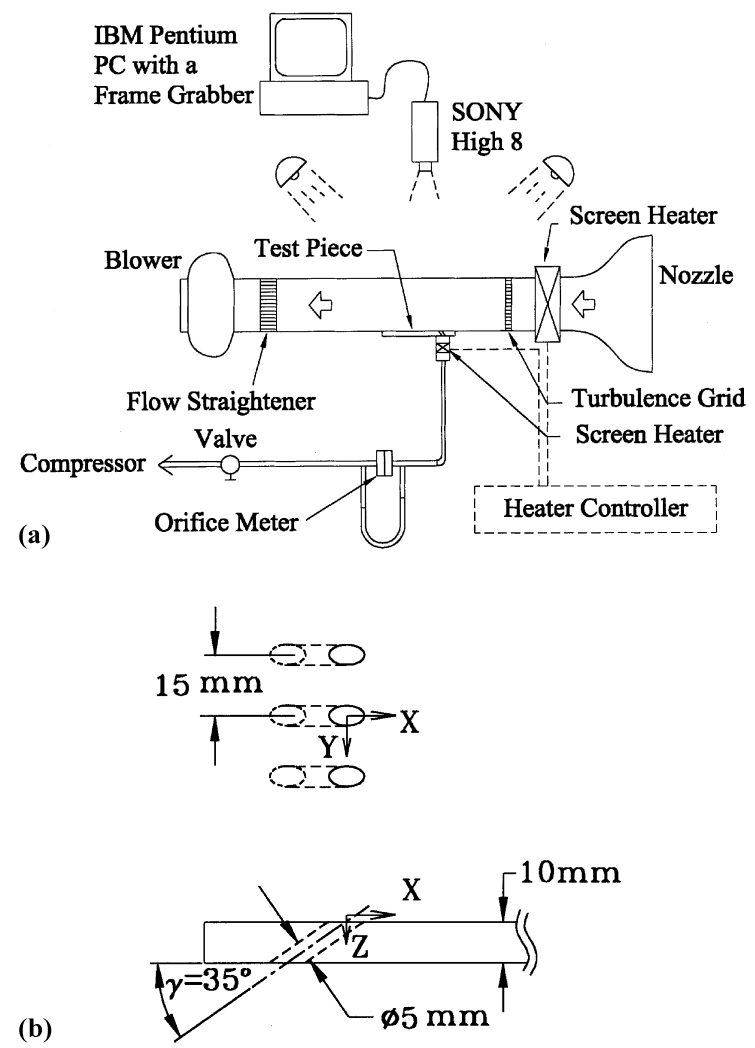

Fig. 2. (a) Schematic view of test facility; (b) cylindrical holes configuration of test piece.

area contraction ratio of 9:1 accelerates the free-stream air. The screen heater was designed to offer step temperature rise as perfect as possible. The heater was constructed by using high resistance, high heating response, and densely interwoven heating wires of $0.1 \mathrm{~mm}$ diameter to ensure that the temperature distribution is uniform and temperature history is steady during the transient experiment. The heating wires were winded on several sensitized and etched circuit boards that were machined to fit the test section to prevent any flow disturbance. The biplanar bar-grid turbulence promoter with a porosity of $50 \%$, formed by crisscrossed $3 \mathrm{~mm}$ diameter metal cylinders, was connected behind the heater at where $450 \mathrm{~mm}$ upstream of the injection holes of test piece. The test section had a square cross-section area of $100 \mathrm{~mm} \times 100 \mathrm{~mm}$, and the flat plate test piece with coated liquid crystal was placed at the bottom wall of the test section. The test section and the test piece were made of Plexiglass for the convenience of light spreading, observation, image capturing, and also to minimize any conduction loss. A flow straightener was positioned to the rear end of test section, and then an axial fan was connected as the driving source of flow field. The flow straightener can prevent the non- uniformity of flow field in the test section from any induced downstream vortex by the fan.

The injection hole configuration is shown in Fig. 2(b). The injection hole diameter is $d=5 \mathrm{~mm}$. The included angle projected in $X Z$-plane between the injection hole direction and $X$-direction is $\gamma=35^{\circ}$ (so-called "inclination angle"), and the included angle projected in $X Y$-plane between the injection hole direction and $X$-direction is $\beta=0^{\circ}$ (so-called "spanwise angle"). The hole length-to-diameter ratio $(L / d)$ is 3.5 and the pitch-to-diameter ratio $(P / d)$ is 3 . The analyzed region was extended to $X / d=20$.

The free-stream velocity was measured by a hot film anemometer (Dantec, Flow Meter 54N60). Both the turbulent intensity and displacement thickness of freestream were measured by a TSI IFA-100 anemometer with hot-wire probes of TSI 1210-T1.5 and TSI 1218T1.5, respectively. Transient free-stream temperature history was measured by a thermocouple and recorded by a data logger (Gulton Rustrak, Rustrak-Ranger II). All the above-described measurements were conducted at $15 \mathrm{~mm}$ upstream from the injection hole.

The injection flow was supplied by a reciprocatingtype compressor that provides an airflow rate of 0.0018 $\mathrm{m}^{3} / \mathrm{s}$ at an operating pressure of $7 \mathrm{~atm}$. The flow rate was adjusted by a needle valve and measured by a calibrated flange-type orifice. Passing through the orifice, injection flow entered a settling chamber. A porous plate with high flow resistance was placed in the settling chamber to assure the uniformity of injection flow during ejection. Besides, a screen heater in the chamber offers the step temperature rise of injection flow. A thermocouple was placed in the chamber to measure the temperature that was recorded continuously by a data logger.

For the image processing system, a Sony Hi8 camera captures and records the liquid crystal color change image at a rate of 30 frames per second. As the recorded tape is played, the image signals are captured by a frame grabber in a Pentium personal computer. The Green value based image processing software analyzes and outputs the color change time from the beginning of test to the threshold Green value of every pixel. The color change time will be used in the later analysis to determine both $h$ and $\eta$. The threshold Green value in this experiment was set at $70 \%$ position from the lowest Green value at room temperature to the peak Green value as temperature rise.

The captured image of the color change of liquid crystal will be clearer on a black background. Therefore, black paint was first sprayed on the back surface of the plexiglass test piece. The encapsulated liquid crystal liquid (Hallcrest, BM/R38C5W/C17-10) was loaded in the compressor-connected airbrush, and uniformly sprayed a thin layer of around several $\mu \mathrm{m}$ on the test surface. 
The test piece with coated liquid crystal was assembled to the test section after liquid crystal calibration. The axial fan and compressor were adjusted, respectively to the required flow rates for the free-stream and injection flow. The transient test began when the freestream and injection flow screen heaters were switched on. Simultaneously, the liquid crystal color change history was captured by the video camera, and the data logger recorded the transient temperature history of free-stream and injection flow. After liquid crystal color change completes, the test section and test piece has to be cooled down to the room temperature for the next test.

For the data analysis, the recorded videotape was analyzed by the image processing software to obtain the color change time files of every pixel when it reached the threshold temperature. Finally, the ESTs of free-stream and injection flow in Eqs. (12) and (13) for each test will be calculated, and the $h$ and $\eta$ can then be obtained by solving Eqs. (15) and (16) for every pixel.

\section{Experiment condition}

The free-stream airflow velocity was fixed at $7.8 \mathrm{~m} / \mathrm{s}$. The free-stream Reynolds number $\left(R e_{\mathrm{d}}\right)$ based on the injection hole diameter is 2200 . The free-stream turbulent intensity $(T u)$ is $2.3 \%$, and the displacement thickness to hole diameter ratio is $\delta_{1} / d=0.22$. The blowing ratio $(M)$, defined as the momentum ratio of injection flow to free-stream flow $\left(\rho_{\mathrm{c}} u_{\mathrm{c}} / \rho_{\mathrm{m}} u_{\mathrm{m}}\right)$, was fixed at 0.5 . For the present heating system, the free-stream temperature rose to $56^{\circ} \mathrm{C}$ at about $6 \mathrm{~min}$ after the screen heater was switched on. The injection temperatures were $36^{\circ} \mathrm{C}$ for the first test and $86^{\circ} \mathrm{C}$ for the second test. All the uncertainties of experiment conditions were listed in Table 1.

For each test case, a total number of 1320 pixels were analyzed in this experiment. The color changes are all completed within 3-7 min for the whole measurements. For the first test with longer color change time due to

Table 1

Uncertainties of measured parameters

\begin{tabular}{ll}
\hline Parameters & Uncertainty \\
\hline$u_{\mathrm{m}}$ & $1.2^{\%}$ \\
$R e_{\mathrm{d}}$ & $3.4 \%$ \\
$T u$ & $4.5^{\circ} \%$ \\
$M$ & $5.3 \%$ \\
$\delta_{1} / d$ & $3.6^{\circ} \%$ \\
$T_{\mathrm{m}}$ & $0.7^{\circ} \mathrm{C}$ \\
$T_{\mathrm{c}, 1}$ & $0.2^{\circ} \mathrm{C}$ \\
$T_{\mathrm{c}, 2}$ & $1{ }^{\circ} \mathrm{C}$ \\
$T_{0}$ & $0.1^{\circ} \mathrm{C}$ \\
$T_{\mathrm{w}}$ & $0.1^{\circ} \mathrm{C}$ \\
$t$ & $0.1 \mathrm{~s}$ \\
$\sqrt{\alpha / k}$ & $3 \%$ \\
\hline
\end{tabular}

low injection temperature, the 1-D semi-infinite assumption is still applicable by the order analysis of governing equation.

\section{Uncertainty analysis}

According to Kline and McClintock [13], if the direct variables are partially correlated, the worst-case error will be adopted to estimate the total uncertainty of the derived variables (local $h$ and $\eta$ in the present study)

$w_{h}=\sum_{\phi}\left|\left(\frac{\partial h}{\partial \phi}\right) w_{\phi}\right|$,

$w_{\eta}=\sum_{\phi}\left|\left(\frac{\partial \eta}{\partial \phi}\right) w_{\phi}\right|$

where $\phi$ represents the direct variables $\left(T_{\mathrm{w}}, T_{0}, T_{\mathrm{c}, 1}, T_{\mathrm{c}, 2}, T_{\mathrm{m}}, t, \sqrt{\alpha} / k\right)$ as listed in Table 1 , and $w_{\phi}$ represents the individual uncertainty of $\phi$.

The total uncertainties of derived variables propagated by the uncertainties of these direct variables are shown in Table 2. At the position far from the injection hole, where $h=22$ and $\eta=0.11$, the total uncertainties of $h$ and $\eta$ are $8.1 \%$ and $10.3 \%$, respectively. At position near the injection hole, where $h=35$ and $\eta=0.22$, the total uncertainties of $h$ of $8.3 \%$ is almost unchanged but $\eta$ is decreased to $8.1 \%$. The uncertainty analysis was considered at $95 \%$ confidence interval. The contributions of $T_{\mathrm{m}}, T_{0}$, and $T_{\mathrm{c}}$ in the total uncertainty of $\eta$ are almost equal.

\section{Results and discussion}

\subsection{The verification of EST method}

In general experimental condition or physical system, the variation of $h$ is estimated to be of first order. For example in the present test model, the range of $h$ values are distributed around 20-32 (Fig. 4(a)) at a blowing ratio of $M=0.5$ and $R e_{\mathrm{d}}=2200$. Fig. 3 shows the measured temperature history of free-stream. Three calculated EST curves for free-stream by Eq. (12) at given values of $h_{\mathrm{EST}}=10, h_{\mathrm{EST}}=20$ and $h_{\mathrm{EST}}=50$ are also shown. The EST curve is always lower than the practically measured temperature history curve at any time instance, and slightly increases with the increase of

Table 2

Total uncertainties of $h$ and $\eta$

\begin{tabular}{llc}
\hline Nominal values & $h(\%)$ & $\eta(\%)$ \\
\hline$h=22, \eta=0.11$ & 8.1 & 10.3 \\
$h=35, \eta=0.22$ & 8.3 & 8.1 \\
\hline
\end{tabular}




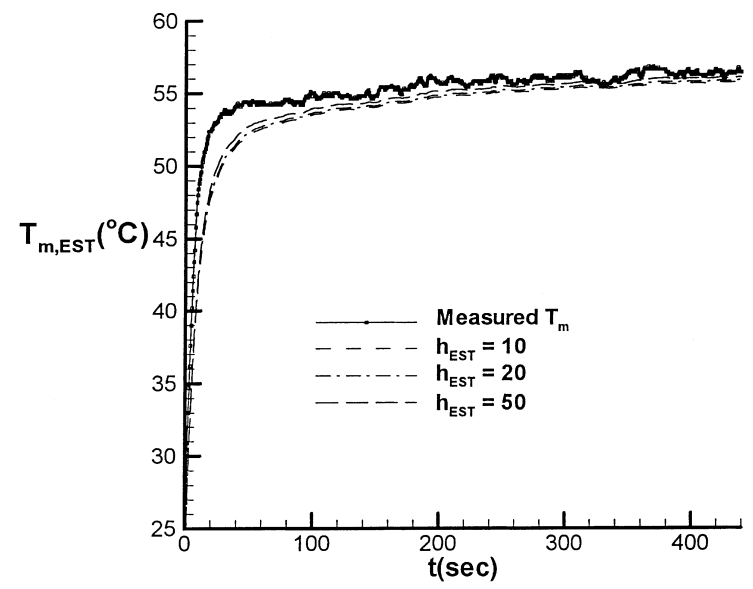

Fig. 3. The relation between measured temperature rise and EST curve at different $h_{\mathrm{EST}}$ values for the free-stream.

$h_{\mathrm{EST}}$. The bias between EST curves of $h_{\mathrm{EST}}=10$ and $h_{\mathrm{EST}}=50$ at $400 \mathrm{~s}$ is only $0.15^{\circ} \mathrm{C}$, much smaller than the error caused by the free-stream heating system. The influences of ESTs with different $h_{\mathrm{EST}}$ on the final results of $\bar{h}$ and $\bar{\eta}$ are respectively shown in Figs. 4(a) and (b). A comparison of the results obtained by both the Duhamel's superposition and by the EST method is also shown in both figures. Spanwise averaged heat transfer coefficient $(\bar{h})$ and film cooling effectiveness $(\bar{\eta})$ were calculated by the $h_{\mathrm{EST}}=20$ and $h_{\mathrm{EST}}=50$, respectively. The two curves almost merge together in both Fig. 4(a) and (b). The maximum bias of $\bar{h}$ is only $1.31 \%$ and $\bar{\eta}$ is only $0.94 \%$. However, the variation range of $h_{\mathrm{EST}}=20$ 50 has already covered the actual range of $h=20-32$ as shown in Fig. 4(a). Therefore, the ESTs are proved to be insensitive to the $h_{\mathrm{EST}}$ in both Eqs. (12) and (13). Moreover, the results obtained by the present EST method also show very good agreement with the results of Duhamel's superposition method.

For experimental application, the $h_{\mathrm{EST}}$ value in EST can be assigned an estimated constant value according to the researcher's test conditions, and the EST can be regarded as a function of time with negligible error. In this experiment, $h_{\mathrm{EST}}$ is fixed at a value of 20 in Eqs. (17) and (18) for further data analysis.

\subsection{The advantages of the equivalent step temperature method}

The validation of the assumption that EST is a function of time only can lead to the simplification of the program and reduce the processing time. The EST method can then be completely independent as a preprocess. Although it takes additional time to calculate the ESTs in this pre-process, the compensation benefit will be higher in most cases. Since the iteration cal-

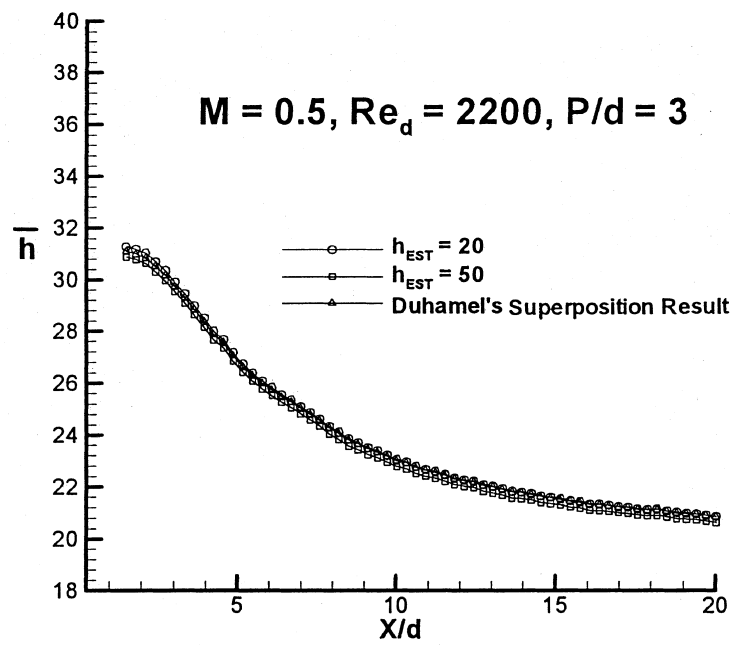

(a)

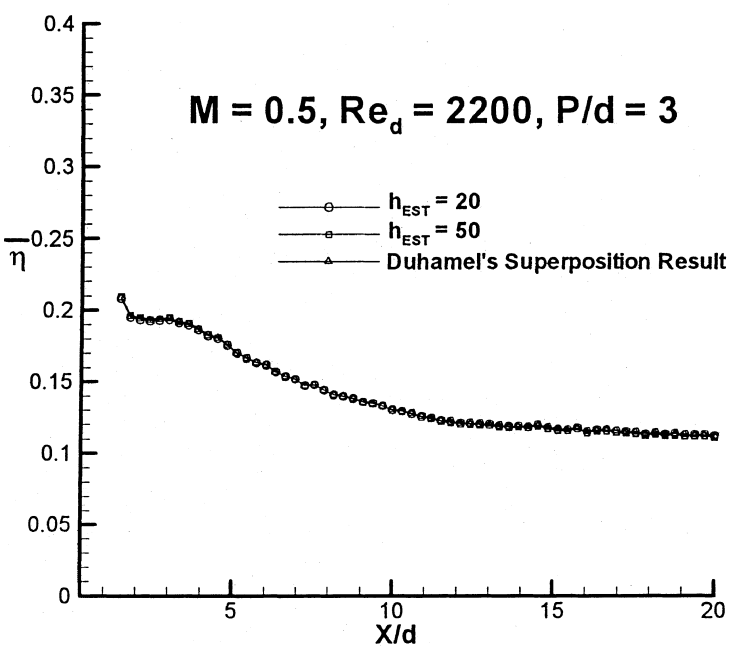

(b)

Fig. 4. (a) $\bar{h}$, and (b) $\bar{\eta}$ results calculated by different $h_{\mathrm{EST}}$ values of EST method and by the Duhamel's superposition method.

culation at every local pixel can be avoided by applying EST, for the cases with high pixel numbers and high color change time, the calculation time would be considerably saved.

Several $10-100 \mathrm{~s}$ are generally taken for one test in the transient liquid crystal experiment. As long as the 1-D semi-infinite approximation is valid, the EST method is able to deal with the longer period of color change in the transient experiment. Because the EST is processed independently, higher sampling density of the temperature rise history could be requested to attain the required precision without increasing the processing 
time in solving $h$ and $\eta$ in Eqs. (15) and (16). Besides, for the multi-test transient liquid crystal experiment [11], the regression analysis that can effectively reduce error, would become difficult to be handled through the conventional iteration method due to large amount of data. Therefore, the simple, independent, and low error characteristics of EST can efficiently improve the data reduction procedure, and accurate results are obtainable.

In the present experiment, the data analysis was performed on a Pentium II $300 \mathrm{MHz}$ personal computer. The total time taken for color change was in 3-7 min and a small amount of 1320 pixels were analyzed. For each EST curve, either the increase in the sampling density of temperature rise history or the color change time will increase the time needed for EST calculation. As compared to the conventional Duhamel's superposition method, the total processing time has been saved up to $80 \%$ in solving $h$ and $\eta$ in the present experiment.

\subsection{The evaluation of the step heating equipment by EST}

The EST can be used to examine the degree of idealization of the practical temperature history in performing the step temperature rise, as shown in Fig. 3. To check whether the measured temperature rise curve can be regarded as a step temperature rise, the ESTs of both the free-stream temperature rise and the injection temperature rise ought to be calculated in advance. For an ideal step temperature rise, the temperature rise curve will completely coincide with its EST curve. However, the practical measured temperature curve will not merge with its EST curve, especially at the early period of measurement. The region before the two curves merge indicates the imperfections of the heating equipment. When the times taken to complete the color change on every pixel are located within the merged range of curves, it represents the good quality of the heating system, and the measured temperature can be regarded as the ESTs. Under this situation, the Duhamel's superposition is not needed and the actual temperature rise can be substituted into the Eqs. (15) and (16) for calculations. For the measured free-stream temperature rise in the present experiment, the EST curve achieves $99 \%$ of the averaged temperature curve at around $250 \mathrm{~s}$. That is, the system can be regarded as an ideal step heating system after $250 \mathrm{~s}$. A non-ideal temperature rise should be considered at those pixels that completed the color change before $250 \mathrm{~s}$, and a Duhamel's superposition modification would be needed.

As a result, the EST method can be used to verify the relationship between the heating system and the time needed by a liquid crystal to complete the color change in the measurement. In practice, this analysis will con- tribute to the improvement of a heating system and also the choosing of a liquid crystal for a specific use in a measurement system.

\section{Conclusions}

Film cooling measurements were conducted on a flat plate with an injection angle of $35^{\circ}, p / d=3, M=0.5$, $T_{\infty}=56^{\circ} \mathrm{C}$, and $R e_{\mathrm{d}}=2200$. For the new data reduction method, an EST method is introduced to replace the Duhamel's superposition method. With negligible additional errors, the present method can save up to $80 \%$ of the calculation times needed for obtaining data from 1320 measured locations as compared with the one using the Duhamel's superposition method under the present test conditions.

Moreover, the EST method can also offer a quantitative standard for the idealization of the heating equipment to improve the experimental system.

\section{References}

[1] J.W. Baughn, Liquid crystal methods for studying turbulent heat transfer, Int. J. Heat Fluid Flow 16 (1995) 365-375.

[2] R.E. Critoph, M.K. Holland, M. Fisher, Comparison of steady state and transient methods for measurement of local heat transfer in plate fin-tube heat exchangers using liquid crystal thermography with radiant heating, Int. J. Heat Mass Transfer 42 (1999) 1-12.

[3] J.W. Baughn, J.E. Mayhew, M.R. Anderson, R.J. Butler, A periodic transient method using liquid crystals for the measurement of local heat transfer coefficients, ASME J. Heat Transfer 120 (1998) 772-777.

[4] Z. Wang, P.T. Ireland, T.V. Jones, R. Davenport, A color image processing system for transient liquid crystal heat transfer experiment, ASME J. Turbomachinery 118 (1996) 421-427.

[5] M.K. Chyu, H. Ding, J.P. Downs, F.O. Soechting, Determination of local heat transfer coefficient based on bulk mean temperature using a transient liquid crystals technique, Experimental Thermal Fluid Sci. 18 (2) (1998) 142-149.

[6] J. Wolfersdorf, R. Hoecker, C. Hirsch, A data reduction procedure for transient heat transfer measurements in long internal cooling channels, ASME J. Heat Transfer 120 (1998) 314-321.

[7] R.J. Vedula, D.E. Metzger, A method for the simultaneous determination of local effectiveness and heat transfer distributions in three temperature convection situations, ASME paper, 1991, 91-GT-345.

[8] S.V. Ekkad, D. Zapata, J.C. Han, Heat transfer coefficients over a flat surface with air and $\mathrm{CO}_{2}$ injection through compound angle holes using a transient liquid crystal image method, ASME J. Turbomachinery 119 (1997a) $580-586$ 
[9] S.V. Ekkad, D. Zapata, J.C. Han, Film effectiveness over a flat surface with air and $\mathrm{CO}_{2}$ injection through compound angle holes using a transient liquid crystal image method, ASME J. Turbomachinery 119 (1997b) 587-592.

[10] Y. Yu, M.K. Chyu, Influence of gap leakage downstream of the injection holes on film cooling performance, ASME J. Turbomachinery 120 (1998) 541-548.

[11] U. Drost, A. Bölcs, A. Hoffs, Utilization of the transient liquid crystal technique for film cooling effectiveness and heat transfer investigations on a flat plate and a turbine airfoil, ASME paper, 1997, 97-GT-26.

[12] T.V. Jones, Definition of heat transfer coefficients in the turbine situation, in: Proceedings of the Institution of Mechanical Engineers, European Conference, Birdcage Walk, London, C423/046, 1991, pp. 201-206.

[13] S.J. Kline, F.A. McClintock, Describing uncertainties in single sample experiments, Mech. Eng. 75 (1953) 3-8. 